\title{
Magnetic Nano-Sized Solid Acid Catalyst Bearing Sulfonic Acid Groups for Biodiesel Synthesis
}

https://doi.org/10.1515/chem-2018-0092

received January 30, 2018; accepted May 4, 2018.

\begin{abstract}
In our approach for magnetic iron oxide nanoparticles surface modification, the fabrication of an inorganic shell, consisting of silica by the deposition of preformed colloids onto the nanoparticle surface and functionalization of these particles, was realized. The magnetic nanoparticles, non-coated and coated with silica layer by Stöber method, are functionalized with chlorosulfonic acid. The magnetic nanoparticles (MNPs), in size of $10-13 \mathrm{~nm}$, could be used as acid catalyst in biodiesel production and show superparamagnetic character. The prepared nanoparticles were characterized by different methods including XRD, EDX, FT-IR and VSM. The catalytic activity of the coated and non-coated solid acids was examined in palmitic acid-methanol esterification as an industrial reaction for biodiesel synthesis. Although thin silica layer results in only a minor obstacle with respect to magnetism, it can accelerate the mass transportation due to its relatively porous structure and magnetic core may be more stable in the acidic reaction medium by means of covering process. Accordingly, coating strategy can be efficient way for allowing applications of MNPs in acid catalyzed esterification.
\end{abstract}

Keywords: Magnetic Nanoparticles; Solid Acid Catalyst; Biodiesel Synthesis; Sulfonic Acid; Esterification.

PACS: 75.75.Cd, 88.20.fk

\section{Introduction}

Rising demand for energy and fuel, row oil reserves crisis and environmental regulations have augmented the

\footnotetext{
*Corresponding author: Sezer Erdem, Uludag University, Physics Department, Bursa, Turkey, E-mail: serdem@uludag.edu.tr

Beyhan Erdem: Uludag University, Chemistry Department, Bursa, Turkey

Ramis Mustafa Öksüzoğlu: Anadolu University, Material Science and Engineering Department, Eskisehir, Turkey
}

interest in biodiesel as a renewable and greener option to diesel based on petroleum [1]. Biodiesel consists of long chain fatty acid esters produced with esterification of free fatty acids with methanol/ethanol or transesterification of triglycerides. In addition to being a renewable resource, biodiesel has many advantages such as a higher flash point, increased lubricity, and a lower emission profile compared with conventional diesel. Also, biodiesel is non-toxic and biocompatible. Because of these attractive properties, biodiesel is a fully environmentally friendly fuel [2].

Despite the currently usage of homogeneous catalytic process for the industrial production of biodiesel, it suffers many drawbacks such as difficulty in separation and the need to deal with the corrosive waste containing acid. Due to the ability to moderate high-acid value of oils as feedstock, heterogeneous acid catalysts are particularly attractive candidates for the biodiesel production process. Therefore, the appropriate heterogeneous solid catalysts for biodiesel production would have a growing interest [3].

Many heterogeneous acid catalysts such as zeolite, ion-exchange resin activated by sulfonation, and sulfated zirconia have been used for acid catalyzed reactions. However, catalysts such as zeolites have micropores and these micropores prevent the diffusion of big reaction components having long alkyl chains. For this reason, zeolites are not recommended for biodiesel synthesis. Ionexchange resins are active strong acids. However, they have low thermal stability and deactivation takes place after only 2-5 hours. Since the stability of catalyst is decreased by the hindering of the smaller pores which are than the reaction components and coke formation, sulfated zirconia also is not appropriate [4]. Because of the low acid loading or the diffusional limitations of porous materials, the current solid acid catalysts show low activity. Due to these reasons, we choose magnetic nanoparticles (MNPs) as the carriers to prepare nano-size solid catalyst containing sulfonic acid groups on the surface. Nanoparticles as heterogeneous catalyst supports have attracted increasing interest, because the particles in nanometer size have large surface area, which provides quite several active and accessible centers. Furthermore, MNPs provide an additional 
advantage in separation and filtration steps for recycling tests [5]. Surface modification of magnetic particles is an elegant way to build a bridge between homogeneous and heterogeneous catalysis. In many organic reactions, silica-coated and sulfuric acid functionalized MNPs as recyclable strong solid acid catalysts facilitate the recovery of the catalyst [6]. MNPs of an ideal size are applied in the form of a stable aqueous suspension, and they should have superparamagnetic character. Superparamagnetism is a phenomenon whereby the magnetic moments of nanoparticles are smaller than a particular thermal energy. Since the particles have almost no coercivity, there are no magnetic interactions between them, which lead to the aggregation of the superparamagnetic nanoparticles. On the contrary, the magnetic interactions between larger particles named as ferri/ferromagnetic prevent to obtain a stable suspension [7].

Successful applications of MNPs highly depend upon their state of being stable especially under low $\mathrm{pH}$ conditions. According to previous studies [8], it is beneficial to use silica coated MNPs to ensure that they are stabilized. The silica layer acts both as a protective layer and scaffold, which makes functionalization possible by means of surface hydroxyl groups. While a thick silica layer would be useful to keep the distances between the core and the surface, it should also be thin enough to maintain the magnetic properties [9].

In the esterification reactions catalyzed by solid acid catalysts, the water, one of the reaction products, not only poisons the surface of the catalyst, but also produces more hydrophilic environment, reducing the performance of the solid acid catalyst. In addition to poisoning of the catalyst's surface in the presence of water molecules, the active acidic sites of the catalysts are also exposed to deactivation, which inhibits the progress of the reactions. Apart from these, there are important parameters affecting the reactions' progress considerably such as the polarities of the reactants and products, hydrophobic-hydrophilic balance on catalyst's surface, and the acidity of catalysts [10].

The goal of this work is to increase the chemical stability of the sulfonic acid functionalized MNPs catalysts at low $\mathrm{pH}$ media by coating silica on the surface of MNPs before functionalization with sulfonic acid. At first, $\mathrm{Fe}_{3} \mathrm{O}_{4}$ nanoparticles are synthesized by co-precipitation of $\mathrm{Fe}^{2+}$ and $\mathrm{Fe}^{3+}$ salt solutions. Then, MNPs are coated with silica layer by Stöber method. Subsequently, the non-coated and coated MNPs are functionalized with chlorosulfonic acid. The catalytic activity of the coated and non-coated solid acids was examined in the palmitic acid-methanol esterification as an industrial reaction for biodiesel synthesis.

\section{Experimental}

\subsection{Chemicals and Instruments}

All chemicals were acquired from Merck or Sigma Aldrich and used as received. The X-ray diffraction patterns were recorded between $10^{\circ}$ and $80^{\circ}(2 \theta)$ in a Rigaku-Rint 2200 X-ray diffractometer (XRD) with $\mathrm{CuK}_{\alpha}$ radiation $(\lambda=0.154$ $\mathrm{nm})$. FT-IR measurements were performed by using a Perkin Elmer-UATR Two series infrared spectrometer. The components of the nanoparticles were analyzed by using energy dispersed X-ray spectrometer (EDX, QuantaBruker AXS). Magnetic properties were examined at room temperature by using a vibrating sample magnetometer (VSM, X9 Microsense) with a maximum applied field of 20 kOe.

\subsection{Preparation of the Magnetic $\mathrm{Fe}_{3} \mathrm{O}_{4}$ Nano- particles (MNPs)}

MNPs were synthesized by chemical co-precipitation method described in the literature [11]. In a typical synthesis, $\mathrm{FeCl}_{3} \cdot 6 \mathrm{H}_{2} \mathrm{O}(0.0216 \mathrm{~mol})$ and $\mathrm{FeCl}_{2} \cdot 4 \mathrm{H}_{2} \mathrm{O}(0.0108$ mol) were dissolved in $100 \mathrm{~mL}$ deionized water at $85^{\circ} \mathrm{C}$ under $\mathrm{N}_{2}$ atmosphere with vigorous stirring. $\mathrm{NH}_{4} \mathrm{OH}$, after being added as base to the $\mathrm{Fe}^{2+}$ and $\mathrm{Fe}^{3+}$ salt solutions, the black precipitate was magnetically separated.

\subsection{Preparation of MNPs Coated by Silica}

$\mathrm{Fe}_{3} \mathrm{O}_{4} \cdot \mathrm{SiO}_{2}$ nanoparticles were prepared according to the reported method [12]. MNPs $(1 \mathrm{~g})$ were firstly dispersed in the mixture of water $(20 \mathrm{~mL})$, ethanol (60 mL), and concentrated $\mathrm{NH}_{4} \mathrm{OH}(2 \mathrm{~mL}, 25 \mathrm{wt} \%)$ and then homogenized by ultrasonic. A solution of TEOS in ethanol $(1 \mathrm{~mL} / 10 \mathrm{~mL})$ was dropped into the dispersion under mechanical stirring. The product, $\mathrm{Fe}_{3} \mathrm{O}_{4} \cdot \mathrm{SiO}_{2}$, was separated by a magnet.

\subsection{Preparation of Sulfonic Acid Functional- ized Magnetic Nanoparticles}

Naked $\mathrm{Fe}_{3} \mathrm{O}_{4}$ and $\mathrm{Fe}_{3} \mathrm{O}_{4} \cdot \mathrm{SiO}_{2}$ samples were ultrasonically dispersed in dry $\mathrm{CH}_{2} \mathrm{Cl}_{2}$. Consecutively, chlorosulfonic acid $(1 \mathrm{~mL})$ was dropped into the dispersion, which was put in the cooled ice bath within $30 \mathrm{~min}$, accompanied by $\mathrm{HCl}$ gas evolving from the reaction vessel. The resulting materials $\left(\mathrm{Fe}_{3} \mathrm{O}_{4} \cdot \mathrm{SO}_{3} \mathrm{H}\right.$ and $\left.\mathrm{Fe}_{3} \mathrm{O}_{4} \cdot \mathrm{SiO}_{2} \cdot \mathrm{SO}_{3} \mathrm{H}\right)$ were separated with the 
help of magnet and washed with dry $\mathrm{CH}_{2} \mathrm{Cl}_{2}$ and ethanol to eliminate the hardly attached substrates as mentioned by Safari and Zarnegar [6].

\subsection{General Procedure for the Esterification of Palmitic Acid with Methanol}

Palmitic acid-methanol esterification was carried out in an isothermal glass reactor as mentioned in the literature [13]. In a typical run, $1.75 \mathrm{~g}$ of palmitic acid was charged into the $100 \mathrm{~mL}$ reactor equipped with a heating jacket and a temperature control unit with an accuracy of $\pm 0.1^{\circ} \mathrm{C}$, and $31.8 \mathrm{~mL}$ of methanol was added. The necessary amount of the solid acid catalyst was taken into the reaction mixture accompanied by refluxing and stirring. The liquid samples $(0.5 \mathrm{~mL})$, withdrawn from the reactor at regular intervals, were analyzed volumetrically after being dispersed in ethanol/diethyl ether mixture. A $0.01 \mathrm{~N}$ alkaline solution of $\mathrm{KOH}$ was used to perform titration. The percentage of palmitic acid conversion $\left(\mathrm{X}_{\mathrm{A}} \%\right)$ was calculated [14].

The acidity of the catalysts was estimated by ionexchange analysis. The catalyst ( $0.05 \mathrm{~g}$ ) was added to $\mathrm{NaCl}$ $(2 \mathrm{M}, 15 \mathrm{~mL})$ aqueous solution and stirred for 1 day. Then, the resulting mixture was titrated by $\mathrm{NaOH}(0.05 \mathrm{M})$.

Ethical approval: The conducted research is not related to either human or animals use.

\section{Results and Discussion}

The diffractograms of naked $\left(\mathrm{Fe}_{3} \mathrm{O}_{4}\right)$ and covered with silica layer $\left(\mathrm{Fe}_{3} \mathrm{O}_{4} \cdot \mathrm{SiO}_{2}\right)$ samples are shown in Figure 1a. The observed XRD patterns appearing at $2 \theta=30.5^{\circ}, 35.8^{\circ}$, $43.4^{\circ}, 53.9^{\circ}, 57.3^{\circ}, 63.1^{\circ}, 71.7^{\circ}$ and $74.8^{\circ}$ and corresponding Miller indices values $\{\mathrm{hkl}\}$ of (220), (311), (400), (422), (511), (440), (620), and (533) reveal cubic iron oxide phase with the structure of inverse spinel ferrite of magnetite (JCPDS file no. 19-0629) [15]. The broad peak $(2 \theta=18$ $25^{\circ}$ ) in the $\mathrm{Fe}_{3} \mathrm{O}_{4} \cdot \mathrm{SiO}_{2}$ sample could be attributed to the amorphous silica in the form of a shell over the $\mathrm{Fe}_{3} \mathrm{O}_{4}$ core and this result is in good agreement with that of Mobaraki et al [10]. The mean particle-size of $\mathrm{Fe}_{3} \mathrm{O}_{4}$ and $\mathrm{Fe}_{3} \mathrm{O}_{4} \cdot \mathrm{SiO}_{2}$ samples was calculated by Scherrer's equation [16], $\mathrm{D}=\mathrm{k} \lambda / \beta \operatorname{Cos} \theta$, resulting in $12.6 \mathrm{~nm}$ and $14.2 \mathrm{~nm}$ for the $\mathrm{Fe}_{3} \mathrm{O}_{4}$ and $\mathrm{Fe}_{3} \mathrm{O}_{4} \cdot \mathrm{SiO}_{2}$ samples, respectively (Table 1). Figure $1 \mathrm{~b}$ shows the XRD diffraction patterns of sulfonic acid functionalized $\mathrm{Fe}_{3} \mathrm{O}_{4}$ and $\mathrm{Fe}_{3} \mathrm{O}_{4} \cdot \mathrm{SiO}_{2}$ samples. The position and relative intensities of all XRD patterns match well with the peaks of the samples shown in Figure 1a,
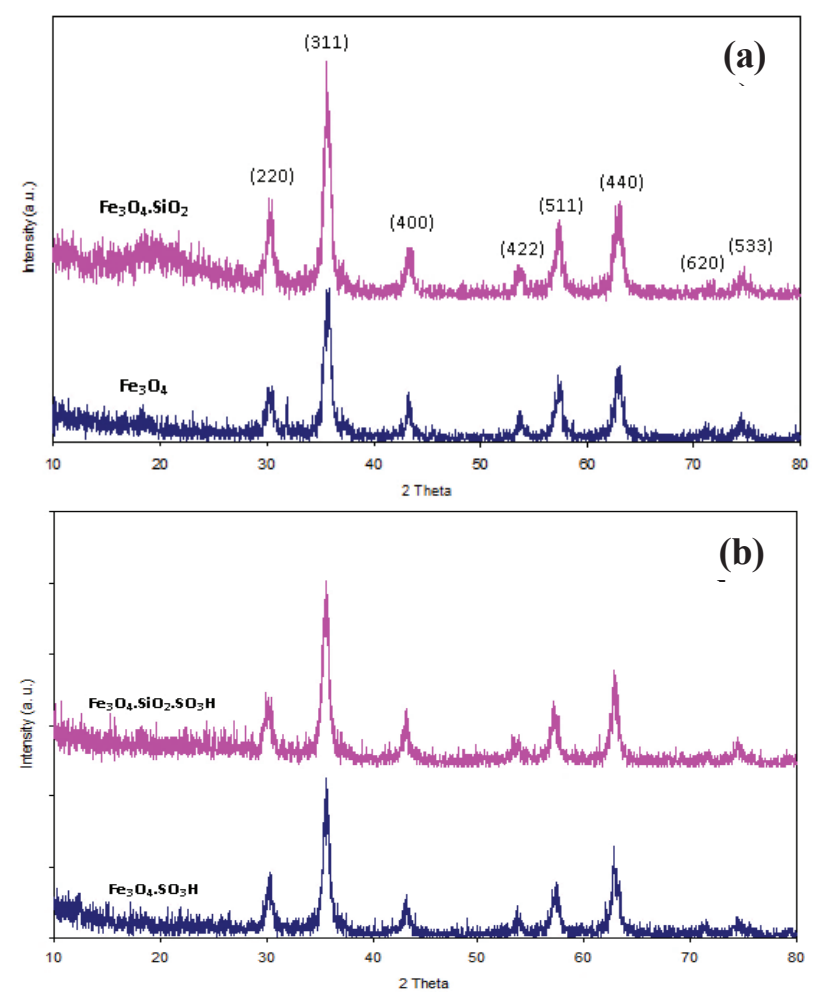

Figure 1: XRD patterns of $\mathrm{Fe}_{3} \mathrm{O}_{4}$ and $\mathrm{Fe}_{3} \mathrm{O}_{4} \cdot \mathrm{SiO}_{2}(\mathrm{a}) ; \mathrm{Fe}_{3} \mathrm{O}_{4} \cdot \mathrm{SO}_{3} \mathrm{H}$ and $\mathrm{Fe}_{3} \mathrm{O}_{4} \cdot \mathrm{SiO}_{2} \cdot \mathrm{SO}_{3} \mathrm{H}(\mathrm{b})$.

indicating the maintenance of the crystalline structure. Consequently, it can be concluded that the frameworks of the $\mathrm{Fe}_{3} \mathrm{O}_{4} \cdot \mathrm{SO}_{3} \mathrm{H}$ and $\mathrm{Fe}_{3} \mathrm{O}_{4} \cdot \mathrm{SiO}_{2} \cdot \mathrm{SO}_{3} \mathrm{H}$ samples remained unchanged [17].

Figure 2a shows the FT-IR spectra of the uncoated $\left(\mathrm{Fe}_{3} \mathrm{O}_{4}\right)$ and coated $\left(\mathrm{Fe}_{3} \mathrm{O}_{4} \cdot \mathrm{SiO}_{2}\right)$ MNPs. In the spectrum of $\mathrm{Fe}_{3} \mathrm{O}_{4}$ MNPs, absorption peaks at 544, 3419 and $1627 \mathrm{~cm}^{-1}$ correspond to the $\mathrm{Fe}-\mathrm{O}$ and $\mathrm{O}-\mathrm{H}$ stretching vibrations, and to the $\mathrm{O}-\mathrm{H}$ bending vibration, respectively. The characteristic absorption peaks for the silica network are in accordance with the literature [18]. The broad and highintensity band at $1077 \mathrm{~cm}^{-1}$ is assigned to the asymmetric stretching of Si-O-Si in $\mathrm{SiO}_{4}$, the band at $797 \mathrm{~cm}^{-1}$ is due to the Si-O-Si symmetric stretching, and the formation of the peak around $450 \mathrm{~cm}^{-1}$ is most likely attributed to the Si-O-Si bending mode. The weak band at $950 \mathrm{~cm}^{-1}$, which was absent in $\mathrm{Fe}_{3} \mathrm{O}_{4}$, is due to the $\mathrm{Si}-\mathrm{OH}$ deformation from the incomplete condensation of TEOS sol [19]. Another FT-IR analysis showed the presence of the $-\mathrm{SO}_{3} \mathrm{H}$ groups attached to the surface of the MNPs (Figure 2b). As shown in Figure $2 \mathrm{~b}$, the FT-IR spectrum of $\mathrm{Fe}_{3} \mathrm{O}_{4} \cdot \mathrm{SO}_{3} \mathrm{H}$ was definitely different from that of $\mathrm{Fe}_{3} \mathrm{O}_{4}$ in Figure 2a. The broad band between 3500 and $3000 \mathrm{~cm}^{-1}$ was attributed to adsorbed water and the broad band in range of $1200-1050 \mathrm{~cm}^{-1}$ was 

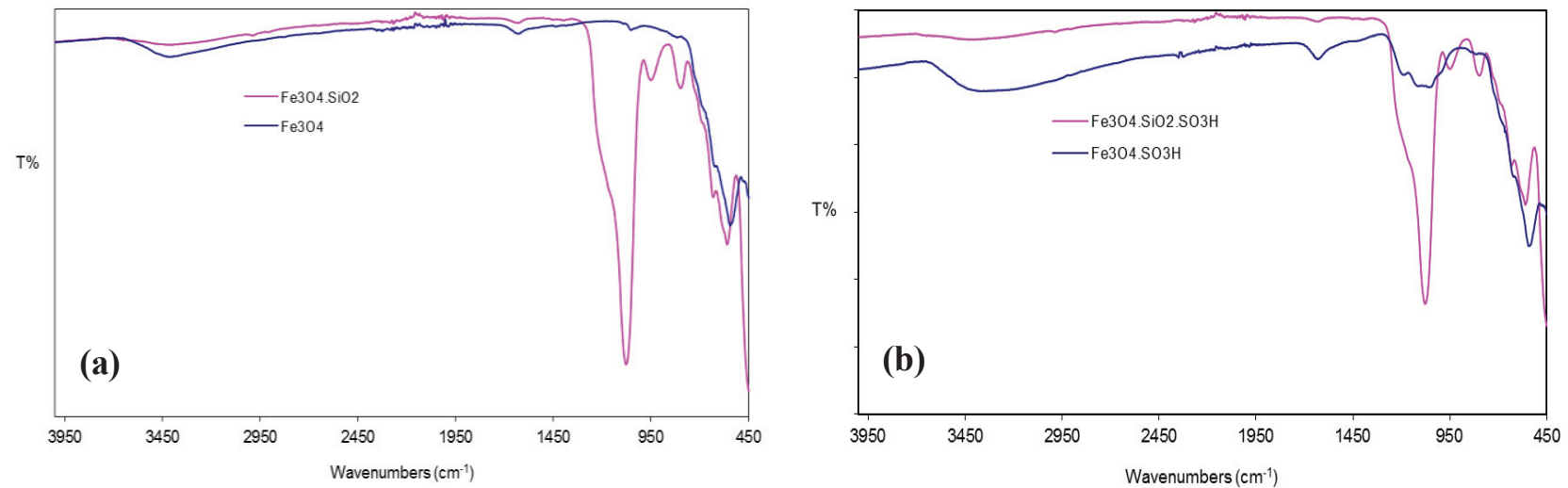

Figure 2: The comparative FT-IR spectra (a) for $\mathrm{Fe}_{3} \mathrm{O}_{4}$ and $\mathrm{Fe}_{3} \mathrm{O}_{4} \cdot \mathrm{SiO}_{2}$; (b) $\mathrm{Fe}_{3} \mathrm{O}_{4} \cdot \mathrm{SO}_{3} \mathrm{H}$ and $\mathrm{Fe}_{3} \mathrm{O}_{4} \cdot \mathrm{SiO}_{2} \cdot \mathrm{SO}_{3} \mathrm{H}$ samples.

attributed to the symmetric $\mathrm{SO}_{2}$ stretching indicating the presence of $\mathrm{SO}_{3} \mathrm{H}$ groups [20]. According to the literature [21], the peaks at 1199 and $1129 \mathrm{~cm}^{-1}$ confirmed the presence of $\mathrm{S}=\mathrm{O}$ group. In our $\mathrm{Fe}_{3} \mathrm{O}_{4} \cdot \mathrm{SO}_{3} \mathrm{H}$ sample, these peaks were observed at 1194 and $1115 \mathrm{~cm}^{-1}$ demonstrating the presence of $\mathrm{SO}_{3} \mathrm{H}$ groups. On the other hand, these bands were covered by stronger absorption of the Si-O band at 1077 $\mathrm{cm}^{-1}$ for the $\mathrm{Fe}_{3} \mathrm{O}_{4} \cdot \mathrm{SiO}_{2} \cdot \mathrm{SO}_{3} \mathrm{H}$ sample. All these observations confirm that the sulfonyl groups have functionalized both of the surfaces of $\mathrm{Fe}_{3} \mathrm{O}_{4}$ and $\mathrm{Fe}_{3} \mathrm{O}_{4} \cdot \mathrm{SiO}_{2}$ samples.

In order to improve the surface reactivity of MNPs, coating by silica is recommended because of the silanol groups (Si-OH) which can be functionalized by further treatment. Therefore the surface concentration of the $-\mathrm{OH}$ groups may be correlated with surface density of the $\mathrm{Si}$ atoms [22]. For this purpose, the components of $\mathrm{Fe}_{3} \mathrm{O}_{4} \cdot \mathrm{SiO}_{2}$, $\mathrm{Fe}_{3} \mathrm{O}_{4} \cdot \mathrm{SO}_{3} \mathrm{H}$ and $\mathrm{Fe}_{3} \mathrm{O}_{4} \cdot \mathrm{SiO}_{2} \cdot \mathrm{SO}_{3} \mathrm{H}$ samples were determined by using EDX as illustrated in Figure 3. According to EDX results, $\mathrm{Fe}_{3} \mathrm{O}_{4}$ nanoparticles were trapped by $\mathrm{SiO}_{2}$ in $\mathrm{Fe}_{3} \mathrm{O}_{4}$. $\mathrm{SiO}_{2}$ sample. The characteristic peaks of Sulphur (S) in $\mathrm{Fe}_{3} \mathrm{O}_{4} \cdot \mathrm{SO}_{3} \mathrm{H}$ and $\mathrm{Fe}_{3} \mathrm{O}_{4} \cdot \mathrm{SiO}_{2} \cdot \mathrm{SO}_{3} \mathrm{H}$ proved that sulfonyl groups were successfully attached onto the surface of both nanoparticles.

Figure $4 \mathrm{a}$ shows the $\mathrm{M}-\mathrm{H}$ hysteresis curves of $\mathrm{Fe}_{3} \mathrm{O}_{4}$ and $\mathrm{Fe}_{3} \mathrm{O}_{4} \cdot \mathrm{SiO}_{2}$ nanoparticles. The saturation magnetization $\left(\mathrm{M}_{\mathrm{s}}\right)$ of the silica coated MNPs represents the magnetic content of $84 \%$ of $\mathrm{Fe}_{3} \mathrm{O}_{4} \cdot \mathrm{M}-\mathrm{H}$ hysteresis curves (Figure 4a, b) have a negligible coercivity and remanence. In addition, the increasing magnetization with the external magnetic field could not reach saturation even at $20 \mathrm{kOe}$. All of these features arise from superparamagnetic character of the nanoparticles [23]. The small decrease (16\%) in the $M_{s}$ value can be attributed to thin silica layer (Table 1). The $\mathrm{M}_{\mathrm{s}}$ value of the $\mathrm{Fe}_{3} \mathrm{O}_{4} \cdot \mathrm{SO}_{3} \mathrm{H}$ and $\mathrm{Fe}_{3} \mathrm{O}_{4} \cdot \mathrm{SiO}_{2} \cdot \mathrm{SO}_{3} \mathrm{H}$ samples obtained from the $\mathrm{M}-\mathrm{H}$ curves shown in Figure $4 \mathrm{~b}$ are 52.6

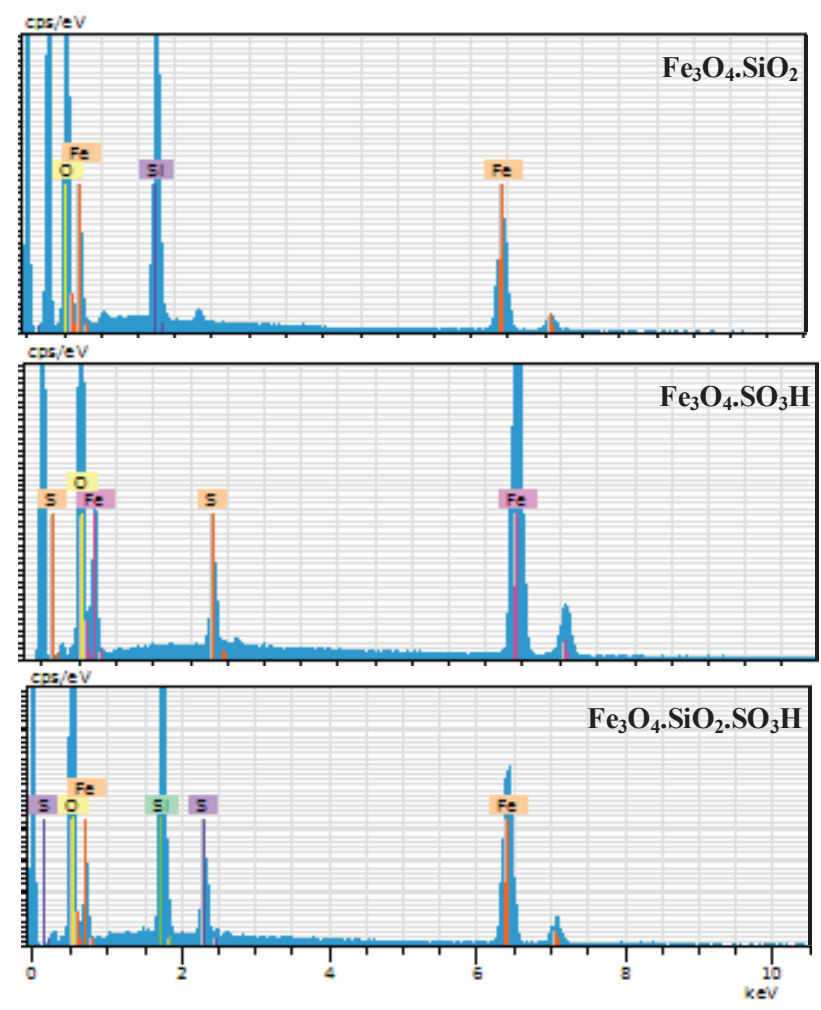

Figure 3: The EDX spectra of $\mathrm{Fe}_{3} \mathrm{O}_{4} \cdot \mathrm{SiO}_{2}, \mathrm{Fe}_{3} \mathrm{O}_{4} \cdot \mathrm{SO}_{3} \mathrm{H}$ and $\mathrm{Fe}_{3} \mathrm{O}_{4} \cdot \mathrm{SiO}_{2}$. $\mathrm{SO}_{3} \mathrm{H}$ nanoparticles.

and $41.1 \mathrm{emu} \mathrm{g}^{-1}$, respectively. These values are smaller in comparison to those of the $\mathrm{Fe}_{3} \mathrm{O}_{4}$ and $\mathrm{Fe}_{3} \mathrm{O}_{4} \cdot \mathrm{SiO}_{2}$ samples, namely, by a factor of about $21 \%$. These results reflect that sulfonic acid functionalization causes the decrease of magnetization. It was also confirmed that the single domain magnetic nanoparticles existed yet already in these acid catalysts [24]. According to mean particle sizes given in Table 1, the larger nanoparticles having higher 


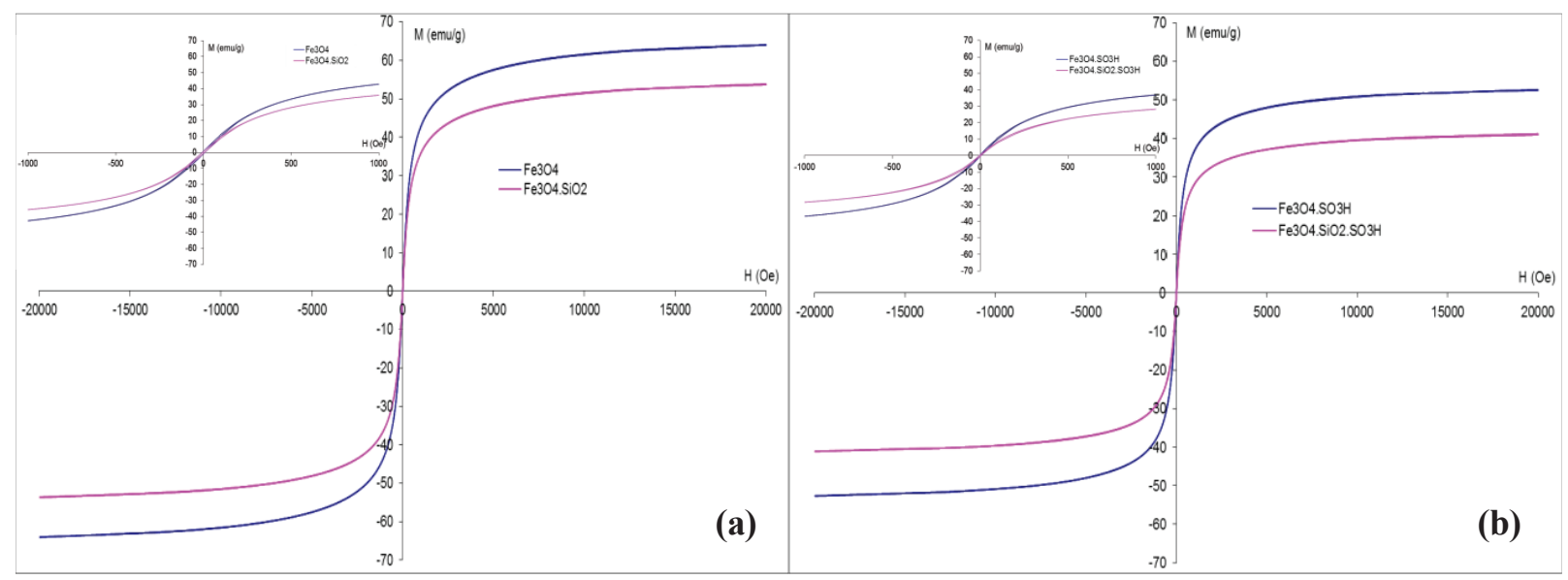

Figure 4: $\mathrm{M}$ - $\mathrm{H}$ hysteresis curves for the $\mathrm{Fe}_{3} \mathrm{O}_{4}$ and $\mathrm{Fe}_{3} \mathrm{O}_{4} \cdot \mathrm{SiO}_{2}(\mathrm{a}), \mathrm{Fe}_{3} \mathrm{O}_{4} \cdot \mathrm{SO}_{3} \mathrm{H}$ and $\mathrm{Fe}_{3} \mathrm{O}_{4} \cdot \mathrm{SiO}_{2} \cdot \mathrm{SO}_{3} \mathrm{H}$ samples (b) at room temperature (-1000 and 1000 Oe inset).

Table 1: Saturation magnetization values based on VSM data and mean particle sizes calculated by XRD.

\begin{tabular}{lll}
\hline & $\begin{array}{l}\text { Saturation Magnetization } \\
(\mathrm{emu} / \mathrm{g})\end{array}$ & $\begin{array}{l}\text { Mean Particle } \\
\text { Size }(\mathrm{nm})\end{array}$ \\
\hline $\mathrm{Fe}_{3} \mathrm{O}_{4}$ & 64.0 & 12.6 \\
$\mathrm{Fe}_{3} \mathrm{O}_{4} \cdot \mathrm{SiO}_{2}$ & 53.7 & 14.2 \\
$\mathrm{Fe}_{3} \mathrm{O}_{4} \cdot \mathrm{SO}_{3} \mathrm{H}$ & 52.6 & 12.9 \\
$\mathrm{Fe}_{3} \mathrm{O}_{4} \cdot \mathrm{SiO}_{2} \cdot \mathrm{SO}_{3} \mathrm{H}$ & 41.1 & 13.3 \\
\hline
\end{tabular}

magnetizations were initially sedimented, resulting in a decrease in the mean size of the nanoparticles. Even with this reduction in the $M_{s}$ values, the catalysts can still be efficiently and easily separated from solution by using an external magnetic force and $\mathrm{M}_{\mathrm{s}}$ values obtained in this study are also consistent with the reported values in the literature $[25,26]$.

According to the expression, $\mathrm{D}_{\operatorname{mag}}=\left(\frac{18 \mathrm{kT}(\mathrm{dM} / \mathrm{dH})_{0}}{\pi \rho \mathrm{M}_{s}^{2}}\right)^{1 / 3}$ the size of the superparamagnetic MNPs was calculated by using the slope of the hysteresis curve near $\mathrm{H}=0$ [27]. Taking the $\mathrm{M}_{\mathrm{s}}$ value obtained from $\mathrm{M}-\mathrm{H}$ curve, the size of $\mathrm{Fe}_{3} \mathrm{O}_{4}$ was estimated as $10.6 \mathrm{~nm}$ which is smaller than that of XRD result $(12.6 \mathrm{~nm})$. The experimental error in the extrapolated $M_{s}$ value and the magnetite density may have contributed to the discrepancy except the contribution of true phase composition [27].

Chlorosulfonic acid, which is used as an acid precursor for functionalizing, provides the acid sites for the $\mathrm{Fe}_{3} \mathrm{O}_{4}$ and $\mathrm{Fe}_{3} \mathrm{O}_{4} \cdot \mathrm{SiO}_{2}$ supports and the selfcondensation of chlorosulfonic acid was verified by the yield of the solid acid catalyst. Increasing the amount of the precursor provides the effective density of acid sites. However, the use of excess chlorosulfonic acid may corrode the magnetic core due to the acid-base neutralization reactions. Although a high acidity was obtained for the $\mathrm{Fe}_{3} \mathrm{O}_{4} . \mathrm{SO}_{3} \mathrm{H}\left(5.1 \mathrm{mmol} \mathrm{g}^{-1}\right.$ with $\pm 2.9 \%$ ) compared to the $\mathrm{Fe}_{3} \mathrm{O}_{4} \cdot \mathrm{SiO}_{2} \cdot \mathrm{SO}_{3} \mathrm{H}\left(4.1 \mathrm{mmol} \mathrm{g}^{-1}\right.$ with \pm $2.9 \%$ ), the catalytic activity of the $\mathrm{Fe}_{3} \mathrm{O}_{4} \cdot \mathrm{SiO}_{2} \cdot \mathrm{SO}_{3} \mathrm{H}$ is higher than that of the $\mathrm{Fe}_{3} \mathrm{O}_{4} \cdot \mathrm{SO}_{3} \mathrm{H}$ (Figure 5). According to experimental results, the $\mathrm{Fe}_{3} \mathrm{O}_{4} \cdot \mathrm{SiO}_{2} \cdot \mathrm{SO}_{3} \mathrm{H}$ was obtained with a solid yield of $75 \%$ and the $\mathrm{Fe}_{3} \mathrm{O}_{4} \cdot \mathrm{SO}_{3} \mathrm{H}$ with $59.5 \%$ which promotes the idea that magnetic core might have been corroded by the chlorosulfonic acid precursor [28]. Esterification of methyl palmitate is a reversible reaction from which the water is arising as byproduct and the higher acid sites belonging to the $\mathrm{Fe}_{3} \mathrm{O}_{4} \cdot \mathrm{SO}_{3} \mathrm{H}$ sample also promoted the reverse reactions causing a longer reaction time compared to $\mathrm{Fe}_{3} \mathrm{O}_{4} \cdot \mathrm{SiO}_{2} \cdot \mathrm{SO}_{3} \mathrm{H}$. Even if the silica covering leads only a little barrier for protecting the MNPs, it can decelerate the mass transport resistance due to its relatively porous structure and magnetic core may be more stable in the low $\mathrm{pH}$ medium by means of the covering process.

\section{Conclusion}

The aim of this study was to synthesize non-coated and silica coated magnetic nanoparticles with activated chlorosulfonic acid, which could be used as catalysts in the esterification and could be separated from reaction medium and collected by magnetic force without centrifugation or filtration. According to the XRD and VSM results, it was concluded that the materials are nano-sized and coated with silica. FT-IR and EDX results confirmed the presence of acid functional groups $\left(-\mathrm{SO}_{3} \mathrm{H}\right)$. 


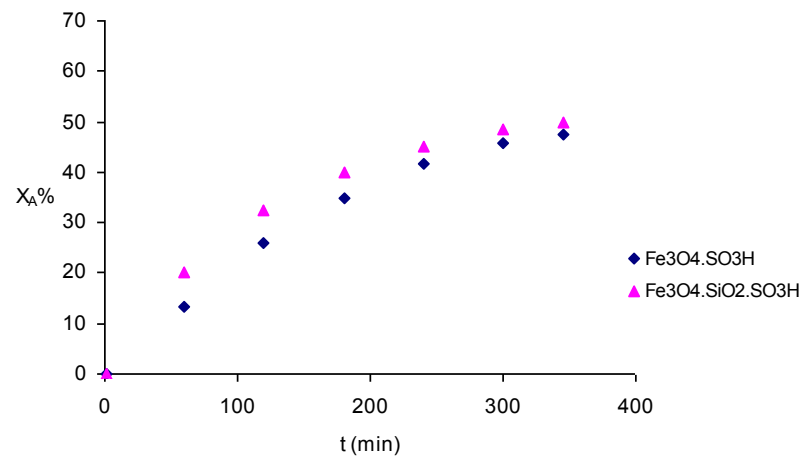

Figure 5: Conversion of palmitic acid as a function of time. Reaction conditions: Palmitic acid: methanol $=1: 33(w / w), 60^{\circ} \mathrm{C}, 3 \mathrm{wt} \%$ catalyst.

Though both of $\mathrm{Fe}_{3} \mathrm{O}_{4} \cdot \mathrm{SO}_{3} \mathrm{H}$ and $\mathrm{Fe}_{3} \mathrm{O}_{4} \cdot \mathrm{SiO}_{2} \cdot \mathrm{SO}_{3} \mathrm{H}$ catalysts efficiently catalyzed the esterification of methylpalmitate, silica coating can accelerate the mass transportation due to its relatively porous structure and magnetic core may be more stable in the acidic reaction medium. In conclusion, low mass transfer resistance, stability, magnetic responsibility, and high reaction efficiency causes the preference of the $\mathrm{Fe}_{3} \mathrm{O}_{4} \cdot \mathrm{SiO}_{2} \cdot \mathrm{SO}_{3} \mathrm{H}$ catalyst.

Acknowledgment: This work was supported by The Commission of Scientific Research Projects of Uludag University, Project number: KUAP(F)-2014/33.

Conflict of interest: Authors state no conflict of interest.

\section{References}

[1] Zillillah, Tan G., Li Z., Highly active, stable, and recyclable magnetic nano-size solid acid catalysts: efficient esterification of free fatty acid in grease to produce biodiesel, Green Chem., 2012, 14, 3077-3086.

[2] Wang H., Covarrubias J., Prock H., Wu X., Wang D., Bossmann S.H., Acid-Functionalized Magnetic Nanoparticle as Heterogeneous Catalysts for Biodiesel Synthesis, J. Phys. Chem. C, 2015, 119, 26020-26028.

[3] Dang T.H., Chen B.H., Optimization in esterification of palmitic acid with excess methanol by solid acid catalyst, Fuel Process. Technol., 2013, 109, 7-12.

[4] Poonjarernsilp C., Sano N., Tamon H., Hydrothermally sulfonated single-walled carbon nanohorns for use as solid catalysts in biodiesel production by esterification of palmitic acid, Appl. Catal. B Environ., 2014, 147, 726-732.

[5] Wang P., Kong A.G., Wang W.J., Zhu H.Y., Shan Y.K., Facile Preparation of Ionic Liquid Functionalized Magnetic Nano-Solid
Acid Catalysts for Acetalization Reaction, Catal. Lett., 2010, 135, 159-164.

[6] Safari J., Zarnegar Z., A magnetic nanoparticle-supported sulfuric acid as a highly efficient and reusable catalyst for rapid synthesis of amidoalkyl naphthols, J. Mol. Catal. A: Chem., 2013, 379, 269-276.

[7] Kralj S., Makovec D., Campelj S., Drofenik M., Producing ultrathin silica coatings on iron-oxide nanoparticles to improve their surface reactivity, J. Magn. Magn. Mater., 2010, 322, 18471853.

[8] Kuzminska M., Carlier N., Backov R., Gaigneaux E.M., Magnetic nanoparticles: Improving chemical stability via silica coating and organic grafting with silanes for acidic media catalytic reactions, Appl. Catal. A: Gen., 2015, 505, 200-212.

[9] Narita A., Naka K., Chujo Y., Facile control of silica shell layer thickness on hydrophilic iron oxide nanoparticles via reverse micelle method, Colloids Surf. A: Physicochem. Eng. Asp., 2009, 336, 46-56.

[10] Mobaraki A., Movassagh B., Karimi B., Hydrophobicityenhanced magnetic solid sulfonic acid: A simple approach to improve the mass transfer of reaction partners on the surface of the heterogeneous catalyst in water-generating reactions, Appl. Catal. A: Gen., 2014, 472, 123-133.

[11] Kassaee M.Z., Masrouri H., Mohavedi F., Sulfamic acidfunctionalized magnetic $\mathrm{Fe}_{3} \mathrm{O}_{4}$ nanoparticles as an efficient and reusable catalyst for one-pot synthesis of $\alpha$-amino nitriles in water, Appl. Catal. A: Gen., 2011, 395, 28-33.

[12] Yang D., Hu J., Fu S., Controlled Synthesis of Magnetite-Silica Nanocomposites via a Seeded Sol-Gel Approach, J. Phys. Chem. C, 2009, 113, 7646-7651.

[13] Ramu S., Lingaiah N., Prabhavathi Devi B.L.A., Prasad R.B.N., Suryanarayana I., Sai Prasad P.S., Esterification of palmitic acid with methanol over tungsten oxide supported on zirconia solid acid catalysts: effect of method of preparation of the catalyst on its structural stability and reactivity, Appl. Catal. A: Gen., 2004, 276, 163-168.

[14] Marchetti J.M., Errazu A.F., Comparison of different heterogeneous catalysts and different alcohols for the esterification reaction of oleic acid, Fuel, 2008, 87, 3477-3480.

[15] Bayat A., Shakourian-Fard M., Ehyaei N., Hashemi M.M., A magnetic supported iron complex for selective oxidation of sulfides to sulfoxides using $30 \%$ hydrogen peroxide at room temperature, RSC Adv., 2014, 4, 44274-44281.

[16] Naeimi H., Nazifi Z.S., A highly efficient nano- $\mathrm{Fe}_{3} \mathrm{O}_{4}$ encapsulated-silica particles bearing sulfonic acid groups as a solid acid catalyst for synthesis of 1,8-dioxooctahydroxanthene derivatives, J. Nanopart. Res., 2013, 15, 2026-2036.

[17] Naeimi H., Nazifi Z.S., Amininezhad S.M., Preparation of $\mathrm{Fe}_{3} \mathrm{O}_{4}$ encapsulated-silica sulfonic acid nanoparticles and study of their in vitro antimicrobial activity, J. Photochem. Photobiol. B: Biol., 2015, 149, 180-188.

[18] Du G.H., Liu Z.L., Xia X., Chu Q., Zhang S.M., Characterization and application of $\mathrm{Fe}_{3} \mathrm{O}_{4} / \mathrm{SiO}_{2}$ nanocomposites, J. Sol-Gel Sci. Techn., 2006, 39, 285-291.

[19] Li Y.S., Church J.S., Woodhead A.L., Moussa F., Preparation and characterization of silica coated iron oxide magnetic nanoparticles, Spectrochim. Acta Part A: Mol. Biomol. Spectrosc., 2010, 76, 484-489. 
[20] Nemati F., Heravi M.M., Rad R.S., Nano- $\mathrm{Fe}_{3} \mathrm{O}_{4}$ EncapsulatedSilica Particles Bearing Sulfonic Acid Groups as a Magnetically Separable Catalyst for Highly Efficient Knoevenagel Condensation and Michael Addition Reactions of Aromatic Aldehydes with 1,3-Cyclic Diketones, Chin. J. Catal., 2012, 33, 1825-1831.

[21] Alizadeh A., Abdi G., Khodaei M.M., Ashokkumar M., Amirian J., Graphene oxide $/ \mathrm{Fe}_{3} \mathrm{O}_{4} / \mathrm{SO}_{3} \mathrm{H}$ nanohybrid: a new adsorbent for adsorption and reduction of $\mathrm{Cr}(\mathrm{VI})$ from aqueous solutions, RSC Adv., 2017, 7, 14876-14887.

[22] Kralj S., Drofenik M., Makovec D., Controlled surface functionalization of silica-coated magnetic nanoparticles with terminal amino and carboxyl groups, J. Nanopart. Res., 2011, 13, 2829-2841.

[23] Karaoglu E., Summak M.M., Baykal A., Sözeri H., Toprak M.S., Synthesis and Characterization of Catalytically Activity $\mathrm{Fe}_{3} \mathrm{O}_{4}-3$ Aminopropyl-triethoxysilane/Pd Nanocomposite, J. Inorg. Organomet. Polym., 2013, 23, 409-417.

[24] Li G., Jiang Y., Huang K., Ding P., Chen J., Preparation and properties of magnetic $\mathrm{Fe}_{3} \mathrm{O}_{4}$-chitosan nanoparticles, J. Alloys Compd., 2008, 466, 451-456.

[25] Naeimi H., Mohamadabadi S., Sulfonic acid-functionalized silica-coated magnetic nanoparticles as an efficient reusable catalyst for the synthesis of 1-substituted $1 \mathrm{H}$-tetrazoles under solvent-free conditions, Dalton Trans., 2014, 43, 12967-12973.

[26] Veisi H., Mohammadi P., Gholami J., Sulfamic acid heterogenized on functionalized magnetic $\mathrm{Fe}_{3} \mathrm{O}_{4}$ nanoparticles with diaminoglyoxime as a green, efficient and reusable catalyst for one-pot synthesis of substituted pyrroles in aqueous phase, Appl. Organometal. Chem., 2014, 28, 868-873.

[27] Yamaura M., Camilo R.L., Sampaio L.C., Macedo M.A., Nakamura M., Toma H.E., Preparation and characterization of (3-aminopropyl) triethoxysilane-coated magnetite nanoparticles, J. Magn. Magn. Mater., 2004, 279, 210-217.

[28] Li J., Liang X., Magnetic solid acid catalyst for biodiesel synthesis from waste oil, Energy Convers. Manage., 2017, 141, 126-132. 